\title{
PREDICTION AND CORRELATION OF AIR PERMEABILITY AND LIGHT TRANSMISSION PROPERTIES OF WOVEN COTTON FABRICS
}

\author{
Ahsan Nazir, Tanveer Hussain, Ali Afzal*, Sajid Faheem, Waseem Ibrahim, Muhammad Bilal \\ Faculty of Engineering \& Technology, National Textile University, Faisalabad-37610, Pakistan \\ * Corresponding author email: aliafzalch89@gmail.com
}

\begin{abstract}
:
The aim of this study was to develop statistical models for predicting the air permeability and light transmission properties of woven cotton fabrics and determine the level of correlation between the two parameters. Plain woven fabrics were developed with different warp and weft linear densities, ends per inch and picks per inch. After desizing, scouring, bleaching, drying and conditioning, the air permeability and light transmission properties of the fabric samples were determined. Regression analysis results showed statistically significant effect of the fabric ends, picks and warp linear density on both the fabric air permeability and light transmission. Correlation analysis was performed to analyze the relation between the fabric air permeability and light transmission. A linear equation was also formulated to find the fabric air permeability through transmission of light intensity. A fitted line plot between the air permeability and light transmission exhibited significant correlation with R-sq. value of $96.4 \%$. The statistical models for the prediction of fabric air permeability and light transmittance were developed with an average prediction error of less than $7 \%$.
\end{abstract}

\section{Keywords:}

Air permeability, Modelling, Transmitted light

\section{Introduction}

Air permeability and visible light transmittance are considered as important parameters in the design of some clothing articles as well as technical products such as tenting, parachute and sailing fabrics, industrial filters, vacuum cleaners and air bags. These parameters are mainly dependent upon geometrical structure of the fabric [1], and different equipment and methods have been developed in the past to evaluate these fabric properties.

In a study, Ogulata [2] successfully employed Darcy's law for capillary model of porous systems to determine the air permeability of the woven fabrics. Xiao et. al. [3] also worked on Darcy's law to predict the air permeability of the different woven fabrics. The predicted results were in good approximation with measured air permeability values. Artificial neural network technique was employed by Behera and Mishra [4] to determine the air permeability of the worsted suiting fabrics. They concluded that radial basis function network accurately predicted the air permeability of the fabric structure using basic fiber characteristics and fabric constructional parameters.

The pore properties of the fabric were investigated by Turan and Okur [5] using image analysis and 2D and 3D geometrical pore models. A strong correlation between geometrical 2D pore model and fabric air permeability was observed. A mathematical model was formulated by Tokarska. She employed neural network technique for the fabric flow properties [6]. Air permeability of the fabric was estimated considering hydraulic diameter of pores, total porosity and number of pores per unit area by Zupinet. al. [7]. They analyzed different weave structures and fabric densities to develop models for fabric air permeability. They observed that predicted values were in high concordance with the actual values of the air permeability of the fabric.

Szmyt and Mikolajczyk [8] used light transmission technique to determine the fabric cover factor on the basis of experimental and theoretical analysis. He worked on Jacquard knitted fabrics and found a good correlation between intensity of transmitted light and fabric cover. Tapias et. al. [9, 10] worked on automatic measurement of woven fabric cover factor using image analysis technique. They also explained that this technique exhibited good agreement between the objective values and subjective results. Cardamone et. al. [11] employed digital image analysis technique to analyze fabric structural parameters. Likewise, Chen, Huang [12], Jasinska and Stempien [13] investigated the pilling properties of the fabric using light projected image analysis. They observed good correlation coefficient between subjective and objective measured grades. Militky et. al. [14] reported that image analysis could be used for determination of air permeability of various weave structures and fiber types. They observed a correlation between air permeability of the woven fabric structure and light transmitted through it, as measured by image analysis.

According to literature, it is obvious that there is no work on the correlation between the fabric air permeability and intensity of the transmitted light. Therefore the aim of this study is to develop a method to predict the air permeability of the fabric using intensity of the transmitted light and correlate them. Transmitted light could be a good predictor of air permeability as it doesn't affect the fabric structure while passing through 
it. On the other hand testing air permeability under pressure (which is not the case in actual use) may alter the structure of the fabric and the yarns. Secondly, if transmitted light could be used as a predictor of air permeability, a more handy testing procedure could be devised without specialized equipment.

\section{Experimental}

The study was carried out on $100 \%$ cotton, plain woven fabrics, developed on $\mathrm{P} 7150$ Sulzer weaving loom by systematic variation in fabric cover factor as shown in Figure 1. The detail of the woven samples is given in Table 1. Fabric samples were desized on a lab scale winch at $60{ }^{\circ} \mathrm{C}$ for 30 minutes, using 5 g/L Bactosol MTN (amylase enzyme by Clariant Ltd.) and 5 g/L Hostapal NI extra (wetting/emulsifying agent by Chromatex Chemicals). Desizing was followed by hot and cold rinsing. Combined scouring and bleaching of samples was carried out in the same machine at $90{ }^{\circ} \mathrm{C}$ for 30 minutes, using $15 \mathrm{~g} / \mathrm{L}$ lab grade caustic soda, $20 \mathrm{~g} / \mathrm{L}$ hydrogen peroxide (35\%), $5 \mathrm{~g} / \mathrm{L}$ Hostapal NI extra, $0.8 \mathrm{~g} / \mathrm{L}$ Stabilizer CT (peroxide bleaching stabilizer by Chromatex Chemicals) and $1 \mathrm{~g} /$ LAlkaquest AM700 (sequestering agent by Alka Chemicals Ltd.). The samples were then rinsed again in hot and cold water. Drying of samples was carried out on a lab scale stenter at $120^{\circ} \mathrm{C}$ for 2 minutes.

The dried and conditioned samples were tested for their construction, intensity of transmitted light (I) and, air permeability (AP). Intensity of transmitted light was evaluated using a lab developed closed light box, with arrangement to mount a fabric sample on it. The box was 15 inches wide and 30 inches high, with a horizontal partition dividing it along its height into two equal parts. The partition contained a hole of $300 \mathrm{~cm}^{2}$, for fixing the frame containing fabric sample. The arrangement allowed passing the light to a lux meter, only through the fabric sample. The schematic diagram of the box is shown in Figure 2.

The intensity of light was measured at a distance of 10 inches below the lamp. With this arrangement the un-interrupted light intensity was 1650 lux (intensity of lamp). Air permeability was assessed according to standard test method ASTM D737. Effect of constructional parameters of the fabrics on the intensity of transmitted light and air permeability was analyzed by statistical data analysis (using Minitab 16 software).

\section{Results and Discussion}

\subsection{Development of Models}

Construction parameters of fabrics along with transmitted light intensity (I) and air permeability (AP) are given in Table 1. The experimental datasets were divided into two subsets; one is for the development of the model whiles the other for the validation of the developed model (highlighted in table 1). The validation datasets were randomly selected and were not used in the development of the prediction models.

The Pearson correlation coefficients between fabric construction parameters and fabric air permeability and transmitted light intensity are given in Table 2 . It is evident from the correlation analysis that statistical significant correlation was observed between fabric air permeability and transmitted light intensity. In addition, ends per inch, picks per inch and weft count were inversely proportional with fabric air permeability as well as with transmitted light intensity. The $p$-value obtained for all the parameters, except for warp count, were less than alpha value $(0.05)$ which showed their statistical significant relation with the response variables.

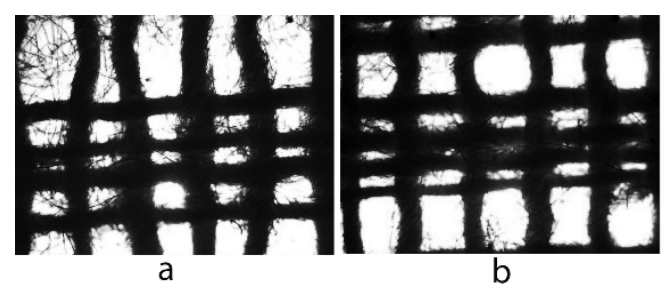

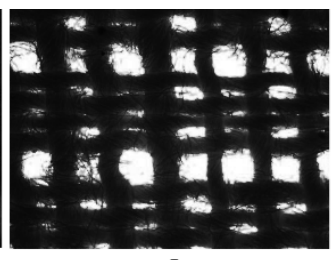

C

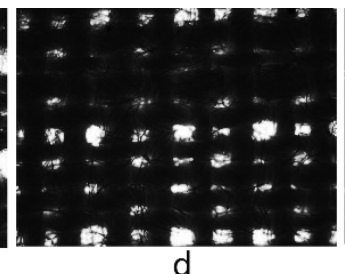

d

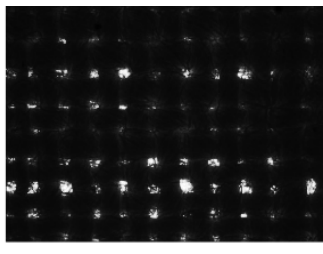

Figure 1. Fabric structures with different fabric cover factors

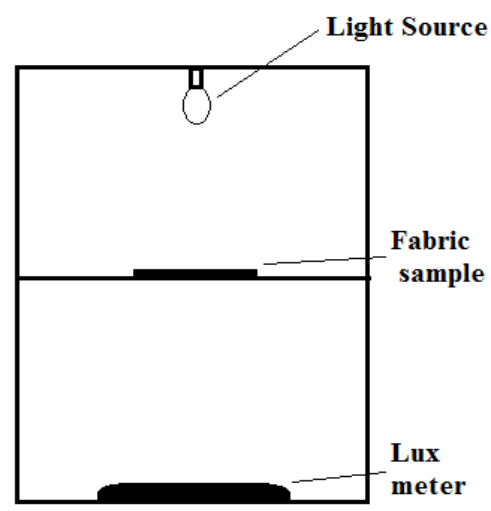

Figure 2. Schematic diagram of light box used for measuring light transmittance of fabric 
Table 1. Construction parameters of the fabric samples with their transmitted light intensity and air permeability

\begin{tabular}{|c|c|c|c|c|c|c|}
\hline Sr. No. & $\mathbf{P}$ & $\mathbf{E}$ & CWP & CWF & I & AP \\
\hline 1 & 38 & 57 & 31.43 & 25.68 & 798.00 & 2120 \\
\hline 2 & 40 & 45 & 22.37 & 21.74 & 830.00 & 2470 \\
\hline 3 & 40 & 45 & 29.03 & 25.07 & 880.23 & 2503 \\
\hline 4 & 40 & 57 & 27.18 & 18.69 & 783.33 & 1740 \\
\hline 5 & 40 & 60 & 23.00 & 26.25 & 814.67 & 1970 \\
\hline 6 & 40 & 62 & 24.41 & 24.18 & 744.00 & 1630 \\
\hline 7 & 40 & 66 & 23.63 & 21.59 & 749.33 & 1810 \\
\hline 8 & 40 & 68 & 19.38 & 24.61 & 816.00 & 2100 \\
\hline 9 & 40 & 68 & 24.41 & 24.08 & 734.00 & 1670 \\
\hline 10 & 40 & 84 & 16.54 & 26.70 & 716.00 & 1300 \\
\hline 11 & 40 & 85 & 26.58 & 23.62 & 640.33 & 710 \\
\hline 12 & 42 & 55 & 19.53 & 20.85 & 850.24 & 2180 \\
\hline 13 & 42 & 56 & 26.06 & 28.61 & 800.54 & 2053 \\
\hline 14 & 48 & 68 & 36.07 & 24.61 & 739.33 & 1470 \\
\hline 15 & 50 & 60 & 20.91 & 18.99 & 722.00 & 1430 \\
\hline 16 & 50 & 60 & 23.39 & 25.11 & 704.67 & 1190 \\
\hline 17 & 50 & 68 & 19.06 & 24.61 & 722.00 & 1410 \\
\hline 18 & 50 & 68 & 23.45 & 20.99 & 663.33 & 1140 \\
\hline 19 & 50 & 70 & 24.18 & 24.58 & 685.00 & 1100 \\
\hline 20 & 50 & 84 & 24.97 & 24.72 & 600.00 & 435 \\
\hline 21 & 50 & 86 & 19.06 & 23.99 & 657.67 & 777 \\
\hline 22 & 57 & 87 & 18.71 & 24.81 & 627.67 & 533 \\
\hline 23 & 60 & 45 & 23.40 & 26.36 & 702.32 & 1230 \\
\hline 24 & 60 & 68 & 19.77 & 25.00 & 643.61 & 977 \\
\hline 25 & 60 & 70 & 22.49 & 25.30 & 648.33 & 803 \\
\hline 26 & 60 & 86 & 24.89 & 25.94 & 581.33 & 269 \\
\hline 27 & 65 & 88 & 26.33 & 24.06 & 556.32 & 230 \\
\hline 28 & 68 & 80 & 24.62 & 27.60 & 597.33 & 280 \\
\hline 29 & 70 & 87 & 18.75 & 24.48 & 607.00 & 305 \\
\hline 30 & 70 & 88 & 23.35 & 26.52 & 558.67 & 172 \\
\hline 31 & 80 & 88 & 23.39 & 26.72 & 524.33 & 86 \\
\hline
\end{tabular}

Where $P=$ Picks per inch, $E=$ Ends per inch, $C_{W P}=$ Warp count (tex), $C_{W F}=$ Weft count (tex), $I=$ Intensity of transmitted light $(\mathrm{Ix}), A P=$ Air permeability $(\mathrm{mm} / \mathrm{sec})$

Table 2. Correlation between fabric construction parameters and fabric air permeability and transmitted light intensity

\begin{tabular}{|c|c|c|c|c|}
\hline \multirow{2}{*}{ Parameter } & Transmitted light intensity & \multicolumn{2}{|c|}{ Air permeability } \\
\cline { 2 - 5 } & PCC & P - value & PCC & P - value \\
\hline P & -0.859 & $0.000^{*}$ & -0.847 & $0.000^{*}$ \\
\hline E & -0.834 & $0.000^{*}$ & -0.867 & $0.000^{*}$ \\
\hline$C_{W P}$ & 0.151 & 0.461 & 0.163 & 0.426 \\
\hline$C_{W F}$ & -0.407 & $0.039^{*}$ & -0.429 & $0.029^{*}$ \\
\hline I & 1.000 & $0.000^{*}$ & 0.982 & $0.000^{*}$ \\
\hline AP & 0.982 & $0.000^{*}$ & 1.000 & $0.000^{*}$ \\
\hline
\end{tabular}

Where * shows statistically significant value and PCC = Pearson correlation coefficient 
Response surface regression analysis was applied on the data for the development of the prediction model. Considering only the statistically significant values, the estimated regression coefficients in coded units for air permeability and transmitted light intensity are given in Table 3.

It is evident from the coefficient values that among the primary weaving factors, the picks per inch have greatest influence on the air permeability as well as on transmitted intensity of light. The negative sign indicates that the input factors have indirect proportion with the response variables. The prediction models developed using the response surface regression analysis in actual factor units has been summarized in Table 4 .

The $\mathrm{R}$ square values for the above developed models well above $95 \%$, which means that more than $95 \%$ variation in the experimental data is explained by the terms included in the model.

\subsection{Transmitted light intensity}

Fabric constructional parameters posed a strong effect on light transmitted through it, as confirmed by $p$-values lower than 0.05 (Table 2) showing the significance of relationship. Transmitted light intensity has an inverse relationship with ends per inch, picks per inch, warp linear density and weft linear density while a direct relationship with warp count square and product of ends and picks per inch (Figure 3 and 4). Increasing the number of yarns per inch, obviously, increases the cover factor of fabric thus decreasing the transmittance of light incident on it.
At lower picks per inch, ends per inch had a strong effect while at higher picks per inch it was nullified. Same was the case for picks per inch, except that the effect was also considerable at higher ends per inch.

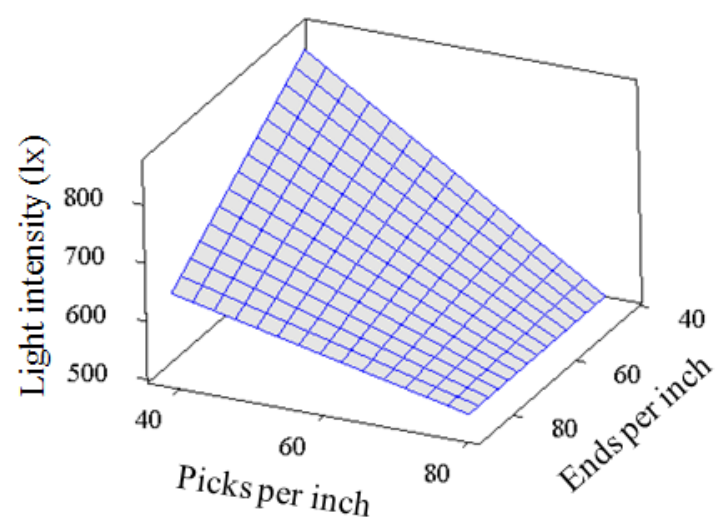

Figure 3. Effect of ends and picks per inch on transmitted light intensity

Overall, the effect of both the warp and weft counts was not found to be as significant as was that of ends and picks per inch (Figure 4). The effect of weft count was found non-significant, which explained that weft yarn count had no statistically significant effect on the transmitted light intensity. With the same ends and picks, when the warp yarn count becomes finer, the inter-yarn spaces increase. However, finer yarns usually have

Table 3. Estimated regression coefficients for air permeability and transmitted light

\begin{tabular}{|c|c|c|c|c|c|c|c|c|}
\hline \multirow{2}{*}{ Term } & \multicolumn{3}{|c|}{ Transmitted light intensity } & \multicolumn{3}{c|}{ Air permeability } \\
\cline { 2 - 9 } & Coefficient & $\begin{array}{c}\text { SE } \\
\text { Coefficient }\end{array}$ & T & P-value & Coefficient & $\begin{array}{c}\text { SE } \\
\text { Coefficient }\end{array}$ & T & P-value \\
\hline Constant & 638.48 & 11.22 & 56.93 & 0.000 & 766.30 & 56.84 & 13.48 & 0.000 \\
\hline E & -54.22 & 13.16 & -4.12 & 0.001 & -196.43 & 89.50 & -2.20 & 0.042 \\
\hline P & -110.98 & 14.19 & -7.82 & 0.000 & -959.29 & 83.11 & -11.54 & 0.000 \\
\hline$C_{\text {WP }}$ & -12.49 & 10.16 & -1.23 & 0.233 & -7.60 & 84.11 & -0.09 & 0.929 \\
\hline$E^{2}$ & & & & & -301.97 & 78.15 & -3.87 & 0.001 \\
\hline$C_{\mathrm{WP}}{ }^{2}$ & 57.20 & 14.49 & 3.95 & 0.001 & 393.99 & 67.14 & 5.87 & 0.000 \\
\hline E.P & 54.10 & 16.49 & 3.28 & 0.004 & 792.86 & 101.56 & 7.81 & 0.000 \\
\hline P.C & & & & & 265.57 & 122.50 & 2.17 & 0.044 \\
\hline
\end{tabular}

Where $\mathrm{T}$ denotes error in coefficient of a term relative to value of that coefficient

Table 4. Regression equations for developed models using uncoded units

\begin{tabular}{|c|r|c|}
\hline Response & Regression Equation & R-Sq. (\%) \\
\hline I & $2049.06-9.70 \mathrm{E}-13.58 \mathrm{P}-32.83 \mathrm{C}_{\mathrm{WP}}+0.60 \mathrm{C}_{\mathrm{WP}}{ }^{2}+0.12 \mathrm{E} \times \mathrm{P}$ \\
\hline $\mathrm{AP}$ & $13140.9-27.49 \mathrm{E}-201.31 \mathrm{P}-295.71 \mathrm{C}_{\mathrm{WP}}-0.65 \mathrm{E}^{2}+4.13 \mathrm{C}_{\mathrm{WP}}{ }^{2}+1.80 \mathrm{E} \times \mathrm{P}+1.33 \mathrm{P} \times \mathrm{C}_{\mathrm{WP}}$ & $98.65 \%$ \\
\hline
\end{tabular}

Where I=transmitted light intensity $(\mathrm{Ix}), \mathrm{AP}=$ air permeability $(\mathrm{mm} / \mathrm{sec}), \mathrm{E}=$ =ends per inch, $\mathrm{P}=$ picks per inch, $\mathrm{C}_{\mathrm{WP}}=\mathrm{warp}$ linear density $($ tex $)$. 
higher twists per inch so the intra-yarn structure of finer yarn is more compact as compared to the coarser yarns. Therefore, the increase in inter-yarn spaces is somewhat compensated with decrease in intra-yarn spaces in case of finer yarns with higher twist.

\subsection{Air permeability}

Air permeability was significantly affected by density of ends and picks, and the warp count, as indicated by their p-values lower than 0.05 in ANOVA (Table 3). The effects of all the parameters were similar to that in case of light transmittance. Increasing ends and picks per inch resulted in a decrease in air permeability. The effect was much stronger in case of ends per inch than that found for picks per inch. Moreover, at higher picks per inch (i.e., $80 \mathrm{P} / \mathrm{I}$ ) the effect of ends per inch was found to diminish. Similar is the case for ends per inch but with a lower intensity, as depicted in Figure 5.

Increasing warp count resulted in slight increase in air permeability through the fabric. This could be attributed to the fact that intra-yarn spacing play its rule due to fluffy nature of coarser yarns allows easier passage of air through the fabric. The effect of weft yarn count was, however, not significant as shown in Figure 6.

\subsection{Validation of Models}

The validation of models was done by developing the samples with construction mentioned in Table 5 and comparing the resultant output variables with those predicted by the models. From the percentage (\%) error for both the output variables it can be inferred that the models offer good accuracy.

Correlation between transmitted light intensity and air permeability

From the results obtained, it was concluded that light intensity and air permeability are interrelated factors and can be predicted from each other also shown in Figure 7.

The correlation between these factors, developed by statistical analysis of data, is shown by Eq. 1 . The $\mathrm{R}^{2}$ for this equation was found to be $96.5 \%$, which shows good predictability of the model.

$$
A P=-4303.55+7.92 \times 1
$$

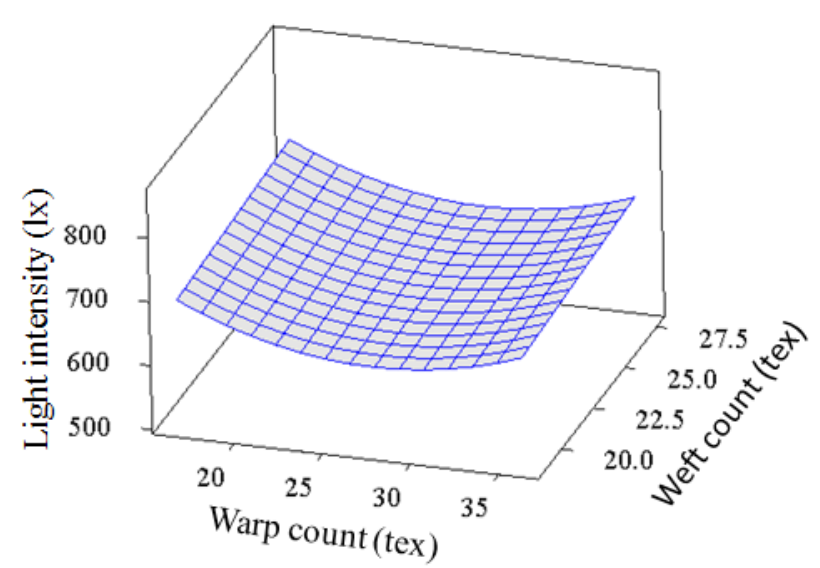

Figure 4. Effect of warp and weft count on transmitted light intensity

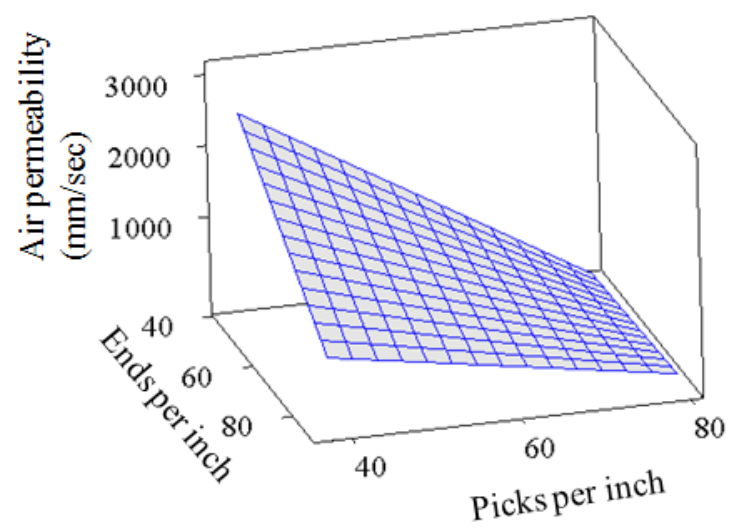

Figure 5. Effect of ends and picks per inch on air permeability

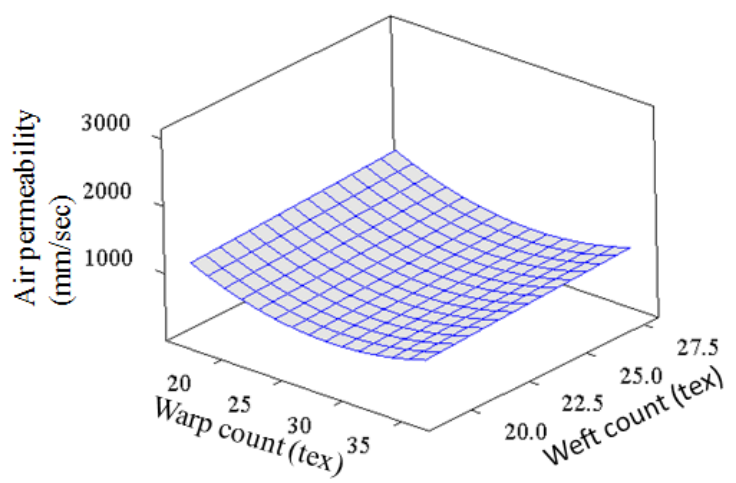

Figure 6. Effect of warp and weft count on air permeability

Table 5. Predicted and actual values of transmitted light intensity and air permeability

\begin{tabular}{|c|c|c|c|c|c|c|c|c|c|c|}
\hline \multirow{2}{*}{ Sr. No. } & \multirow{2}{*}{$\mathbf{P}$} & \multirow{2}{*}{ E } & \multirow{2}{*}{ CWP } & \multirow{2}{*}{ CWF } & \multicolumn{3}{|c|}{ I } & \multicolumn{3}{|c|}{ AP } \\
\hline & & & & & Pred. & Actual & $\%$ Error & Pred. & Actual & $\%$ Error \\
\hline 1 & 40 & 45 & 29.03 & 25.07 & 842.65 & 880.23 & 4.27 & 2204 & 2503.00 & 11.96 \\
\hline 2 & 42 & 55 & 19.53 & 20.85 & 816.31 & 850.24 & 3.99 & 2242 & 2180.00 & 2.83 \\
\hline 3 & 42 & 56 & 26.06 & 28.61 & 775.90 & 800.54 & 3.08 & 1880 & 2053.00 & 3.10 \\
\hline 4 & 60 & 45 & 23.40 & 26.36 & 689.42 & 702.32 & 1.84 & 564 & 1230.00 & 6.62 \\
\hline 5 & 65 & 88 & 26.33 & 24.06 & 566.19 & 556.32 & 1.77 & 215 & 230.00 & 6.38 \\
\hline \multicolumn{5}{|c|}{ Average Error } & \multicolumn{3}{|c|}{2.99} & \multicolumn{3}{|c|}{6.18} \\
\hline
\end{tabular}


Where I=transmitted light intensity (lux) and $A P=$ fabric air permeability $(\mathrm{mm} / \mathrm{sec})$

\section{Conclusion}

In this study, response surface methodology was employed for modelling of transmitted light intensity and air permeability through $100 \%$ cotton plain woven fabrics. Three of the selected input parameters, i.e., ends/inch, picks/inch and warp count, were observed to produce strong effect on output properties. The models developed based on these input variables were found to show good validity. Moreover, it was found that transmitted light intensity and air permeability of the fabrics may be determined from each other with fairly good accuracy because of strong correlation between the two. The accuracy of the correlation equation between them was also confirmed by its high $\mathrm{R}^{2}$ value. So, the models developed in this study can be used, reliably, to predict the transmitted light intensity and air permeability of plain woven cotton fabrics. The model could be a practical and handy tool to predict the air permeability of fabric without disturbing the fabric structure due to pressurized air passing through it as for conventional methods to determine air permeability. However, it may be noted that the model is valid only for range ends, picks and yarn count range and fibre composition used in this study. For other weave structures and compositions further studies are required.

\section{References}

[1] Afzal, A., Hussain, T., Malik, M. H., and Javed, Z. (2014). Statistical model for predicting the air permeability of polyester/cotton blended interlock knitted fabrics. The Journal of The Textile Institute, 105(02), 214-222.

[2] Ogulata, R. T. (2006). Air permeability of woven fabrics. Journal of Textile and Apparel, Technology and Management, 5(2), 1-10.

[3] Xiao, X., Zeng, X., Long, A., Lin, H., Clifford, M., and Saldaeva, E. (2012). An analytical model for throughthickness permeability of woven fabric. Textile Research Journal, 82(5), 492-501.

[4] Behera, B. and Mishra, R. (2007). Artificial neural networkbased prediction of aesthetic and functional properties of worsted suiting fabrics. International Journal of Clothing Science and Technology, 19(5), 259-276.

[5] Turan, R. and Okur, A. (2012). Investigation of pore parameters of woven fabrics by theoretical and image analysis methods. Journal of The Textile Institute, 103(8), 875-884.

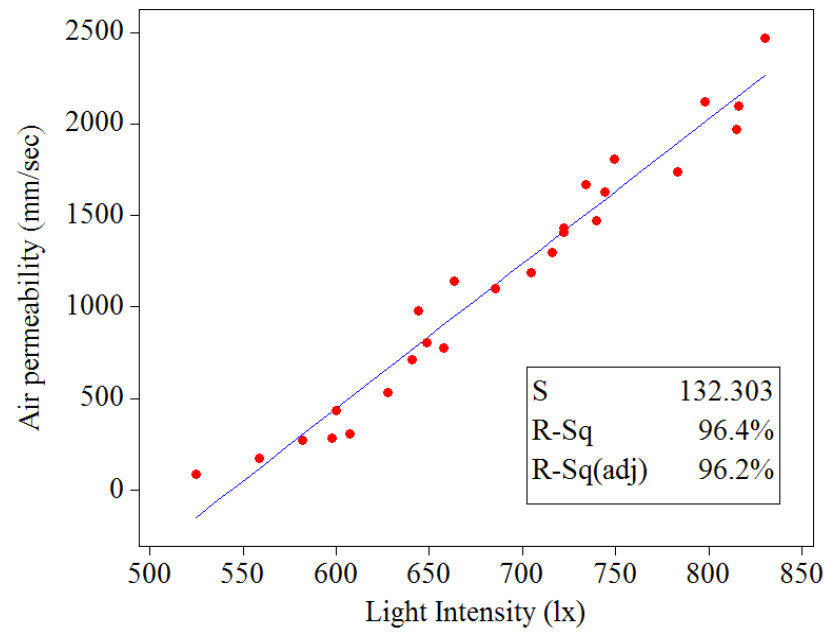

Figure 7. Correlation between transmitted light intensity and air permeability

[6] Tokarska, M. (2004). Neural Model of the Permeability Features of Woven Fabrics. Textile Research Journal, 74(12), 1045-1048.

[7] Zupin, Ž., Hladnik, A., and Dimitrovski, K. (2012). Prediction of one-layer woven fabrics air permeability using porosity parameters. Textile Research Journal, 82(2), 117-128.

[8] Szmyt, J. and Mikolajczyk, Z. (2010). Light transmission through decorative knitted fabrics in correlation with their fabric cover. AUTEX Research Journal, 10(2), 44-48.

[9] Tàpias, M., Ralló, M., Escofet, J., Algaba, I., and Riva, A. (2010). Objective Measure of Woven Fabric's Cover Factor by Image Processing. Textile Research Journal, 80(1), 3544.

[10] Tàpias, M., Ralló, M., and Escofet, J. (2011). Automatic measurements of partial cover factors and yarn diameters in fabrics using image processing. Textile Research Journal, 81(2), 173-186.

[11] Cardamone, J. M., Damert, W. C., Phillips, J. G., and Marmer, W. N. (2002). Digital image analysis for fabric assessment. Textile Research Journal, 72(10), 906-916.

[12] Chen, X. and Huang, X. (2004). Evaluating fabric pilling with light-projected image analysis. Textile Research Journal, 74(11), 977-981.

[13] Jasinska, I. and Stempien, Z. (2013). An alternative instrumental method for fabric pilling evaluation based on computer image analysis. Textile Research Journal, 0040517513512398.

[14] Militky, J., Travnickova, M., and Bajzik, V. (1999). Air permeability and light transmission of weaves. International Journal of Clothing Science and Technology, 11(2/3), 116125. 